\title{
A company's corporate reputation through the eyes of employees measured with sentiment analysis of online reviews
}

\author{
Author(s) \\ Loke, R.E.; Lam-Lion, R. \\ DOI
}

10.5220/0010620603780385

\section{Publication date}

2021

\section{Document Version}

Final published version

\section{License}

CC BY-NC-ND

Link to publication

\section{Citation for published version (APA):}

Loke, R. E., \& Lam-Lion, R. (2021). A company's corporate reputation through the eyes of employees measured with sentiment analysis of online reviews. 378-385. Paper presented at 10th International Conference on Data Science, Technology and Applications, Online . https://doi.org/10.5220/0010620603780385

If you believe that digital publication of certain material infringes any of your rights or (privacy) interests,

please let the Library know, stating your reasons. In case of a legitimate complaint, the Library will make the material inaccessible and/or remove it from the website. Please contact the library:

https://www.amsterdamuas.com/library/contact/questions, or send a letter to: University Library (Library of the University of Amsterdam and Amsterdam University of Applied Sciences), Secretariat, Singel 425, 1012 WP Amsterdam, The Netherlands. You will be contacted as soon as possible. 


\title{
A company's corporate reputation through the eyes of employees measured with sentiment analysis of online reviews.
}

\author{
Loke, R.E. ${ }^{1}$ a a and Lam-Lion, R. \\ ${ }^{1}$ Centre for Market Insights, Amsterdam University of Applied Sciences, Amsterdam, The Netherlands \\ r.e.loke@hva.nl
}

Keywords: Sentiment analysis; corporate reputation; natural language processing; semantic search.

\begin{abstract}
Corporate reputation can be defined as the overall assessment of a company's performance over time (Kircova \& Esen, 2018). Organizations with a positive corporate reputation create a competitive advantage and are more likely to influence customer's behaviors and attitudes (Kircova, 2018). Measuring corporate reputation is an increasingly important area in business studies because the amount of opinions and comments is increasingly growing on the internet and has become very accessible to strangers (Shayaa, 2018). Traditionally, corporate reputation is measured with well-known approaches such as surveys, qualitative interviews, and sample groups (Smith, 2010). Researchers like Fombrun \& Fonzy and Newburry have already drawn attention to a new method of measuring corporate reputation. In Fombrun's most recent research, an instrument was developed to measure corporate reputation and develop predictive models of reputation's impact on stakeholder outcomes (Fombrun, Fonzy, Newburry, 2015). So far, however, there has been little discussion about measuring corporate reputation with sentiment analysis using online reviews. This paper applies sentiment analysis as a suitable method to explore how employees perceive organizations, hence measuring corporate reputation. By using our tool, organizations can adapt to market changes and cater to stakeholders' needs. Also, it can be used to raise awareness for organizations that are unaware of negative reviews online.
\end{abstract}

\section{INTRODUCTION}

Corporate reputation defines itself as the overall assessment of a company's performance over time (Kircova \& Esen, 2018). Organizations with a positive corporate reputation create a competitive advantage and are more likely to influence customer's behaviors and attitudes (Kircova, 2018). Recent studies have shown that corporate reputation is usually measured through qualitative interviews, surveys, and focus groups (Smith, 2010). The purpose of this paper is to measure corporate reputation from online reviews that are publicly available on the web.

A recent study indicated that sentiment analysis could be a useful means of measuring the public's opinion (Shayaa, 2018). The paper highlights that an organization that gathers information about their stakeholders and applying sentiment analysis are doing this to improve the quality of their products (Shayaa, 2018). However, it is also indicated that it is also used to understand better public opinion, or employees' opinion, which is applicable for our purpose.

This paper's main research question is as follows: "How can corporate reputation from the perspective of the employee be measured from online reviews with the help of sentiment analysis?" The question will be answered with both primary research, in section 3, and literature study, in section 2 .

\section{LITERATURE REVIEW}

Many studies have dedicated methods to measure corporate reputation (Fombrun, 1996). Most of them have conducted these studies through qualitative interviews, surveys, and focus groups (Smith, 2010). From a socio-economical perspective, the importance of measuring corporate reputation is crucial. This means that to prevent damaging a brand's image, analytical insights from this study should help assess

https://orcid.org/0000-0002-7168-090X 
the problem that organizations fail to recognize poor corporate reputation (Lange, 2011). If organizations detect negative reviews from an early stage, they can steer a positive message and negative communication exiting the organization.

\subsection{Defining corporate reputation}

Many researchers define corporate reputation. According to Bronn, reputation has many interpretations, but most agree that it is an intangible asset that can build a competitive advantage for a firm (Bronn, 2015). A good reputation can give an organization a competitive advantage (Bronn, 2015). This is because a good reputation is valuable, rare, and cannot be replaced (Bronn, 2015). Other researchers argue that corporate reputation is defined as a stakeholder's overall assessment of a company's performance over time (Kircova, 2018). It reflects multiple stakeholders' perceptions about the organization's effectiveness (Kircova, 2018). Companies with a high reputation create a competitive advantage and are more likely to influence customers' behaviors and attitudes (Kircova, 2018).

According to Smitha, brand associations affect the corporate image and is the company's reputation. A positive brand image can boost consumer confidence in a company, affect decision making, and build loyalty. Companies take great care in managing their brand image because it is a source of value (Smitha, Smith \& Wang 2010). In general, there is an agreement that its stakeholders determine corporate reputation and that it is an intangible asset that creates a competitive advantage and is of high value to an organization. Since it is seen as a valuable asset, damaging the organization with negative reviews might severely damage the organization.

\subsection{Stakeholder Tracking and Analysis: The RepTrak System for measuring corporate reputation}

The RepTrak System describes the importance of using a prototype system that was developed to measure corporate reputation. It is an analytical tool used to track stakeholders' perceptions of companies (Fombrun, 2015). A seven-dimensional framework is described, derived from prior literature that highlights how stakeholders should be managed (Fombrun, 2015). It can be used as a basis to verify which dimensions are touched upon in online reviews that are gathered from the public web. The seven dimensions are:
1. Products and Services refer to the perception that reputation is likely to be affected by the products that an organization offers. A company is usually positively perceived if it offers high-quality products and services (Fombrun, 2015). According to Smith \& Wang, a company's brand name not only indicates the type and quality of products and services offered but also symbolizes the character of the company (Smith, Smith \& Wang, 2010). Consumer perception of a brand can make or break a company (Smith, 2010). A positive brand image can boost consumer confidence in a company, affect decision making, and build loyalty. Online reviews about a product or service are likely to be put online by customers (Smith, 2010). In this particular study, customers were not investigated. Even though customers are not investigated, it is verified whether employees include opinions about the focal organization's products and services in online reviews.

2. Innovation indicates that an innovative organization adds to a positive company reputation and strives to do new things within the organization (Fombrun, 2015). According to Courtright, there are two basic views on innovation. From an organization's point of view, innovation concerns its ability to create new and better products and services (Courtright \& Smudde, 2009). From a market's point of view, innovation is about how it introduces new and better things into the socio-economic systems in which organizations take part. By stating this is meant that innovation can involve employees in the process and could be a topic, they write about in online reviews. The study from Courtright \& Smudde suggests that employees receive multiple messages within and outside the organization and that good corporate communication can prevent negativity exiting the company, even if this is not necessarily about innovation (Courtright, 2009).

3. Workplace suggests that most stakeholders like and respect companies that maintain healthy workplaces and do good for their employees, which is also visible outside the organization (Fombrun, 2015). According to Nolan, an employer brand image refers to the package of functional, economic, and psychological benefits provided by employment, and identified with the employing company (Nolan, 2013). It refers to a person's beliefs about what it would be like to work for a corporation (Nolan, 2013). Fombrun suggests that most stakeholders like and respect companies that maintain good workplaces (Fombrun, 2015). Both studies indicate that the 
workplace can impact the brand's image and can be affected if viewed negatively. Besides, Nolan states that satisfied employees are more likely to commit to long-term involvement and act as ambassadors of the company and give an employer a favorable rating (Nolan, 2013). While being aware of this, it is especially crucial when analyzing online reviews gathered for this research.

4. Governance is considered a key part of reputation management in terms of being transparent and ethical; organizations with corporate governance tend to build more trust with stakeholders (Fombrun, 2015). According to Davis, corporate governance can be defined as the structures, processes, and institutions within and around organizations that allocate power and resource control among participants (Davis, 2005). It could be that these structures, processes, and institutions are also discussed in online reviews.

5. Citizenship is an essential aspect of reputation management since companies are admired for good deeds and building a strategic asset if they participate in, for example, a good cause (Fombrun, 2015). A qualitative study suggests that stakeholders tend to respect and admire a company for their good deeds. For example, good deeds such as health benefits, care plans, and other benefits could lead to a positive corporate review (Orlitzky, 2012).

6. Leadership is a visible quality that aids in a good reputation. A good leader attracts positive media coverage and is more likely to support company activities. Fombrun's study mentions that a good manager could influence employees to have a positive work environment and stimulate employees to bring harmony to the workplace (Fombrun, 2015). Good leadership is very likely to be discussed in reviews since it directly affects employees (Fombrun, 2015).

7. Performance is seen as a signal that influences how stakeholders assess companies. A strong financial performance is positively attributing to an organization's trustworthiness (Fombrun, 2015).

These seven dimensions affect corporate reputation and are necessary to manage and satisfy stakeholders.

\subsection{Risk governance, structures, culture, and behavior: A view from the inside}

A different approach for measuring corporate reputation is to conduct surveys. This study suggests that internal corporate governance and reputation could be measured with surveys held from employees, operating in different business units (Sheedy \& Griffin 2018). It was seen that employees generally provide favorable ratings for training programs, training frameworks, and managers (Sheedy, 2018). In contrast, ratings for remuneration were less favorable (Sheedy, 2018). One of the findings was that leaders play a crucial role in developing culture (Sheedy, 2018). However, the paper indicates that biases occurred because of a higher proportion of males in the surveys. Even though this paper researched the banking sector, surveys were seen as a convenient yet obsolete method to measure reputation.

In our approach, the use of corporate reviews eliminates the bias of managers influencing employees to give favorable answers. Nevertheless, Sheedy's paper indicates that it was challenging to obtain survey access and that a self-selection bias could be present.

\subsection{Sentiment Analysis of Big Data: Methods, Applications, and Open Challenges}

Shayaa, Jaafar, Bahri, Sulaiman, Seuk Wai Chung, Piprani \& Al-Garadi (2018) highlight the development of sentiment techniques and discuss non-technical challenges on how sentiment analysis is applied. The amount of opinions and comments is increasingly growing on the internet and has become accessible to strangers (Shayaa, 2018). Since large amounts of information could be gathered from the internet, text mining is one of the approaches for analyzing text (Shayaa, 2018). Text mining uses Natural Language Processing, knowledge management, data mining, and machine learning techniques to process text documents (Shayaa, 2018). Text mining/analytics are originally conducted for two purposes. The first purpose is to analyze people's sentiment on an issue or phenomenon (Shayaa, 2018). Hence, sentiment analysis goes through massive amounts of data to identify people's attitudes, thoughts, judgments, and emotions on an issue (Shayaa, 2018).

The second purpose is to assess people's opinion on a product, person, event, organization, or topic from a user or group of user perspectives. Similar to sentiment analysis, opinion mining is a natural language processing task that uses an algorithmic technique to recognize content with 
opinions and allocate it to positive, negative, or neutral polarity (Sheedy, 2018).

These studies highlight that an organization that gathers information about their stakeholders and applies sentiment analysis is doing this to improve the quality of their products. However, it is indicated that additional factors might play an active role in better understanding public opinion, or employees' opinion. These factors might include competitors and economic growth. This illustrates that sentiment analysis is a useful means of measuring public opinion and that organizations can recognize public opinion more efficiently with sentiment-driven applications.

\subsection{Journal of Business Research: The role of emotions and conflicting online reviews on consumers' purchase intentions.}

A recent study of online reviews demonstrates the importance of online review content. It stresses the relevance of encouraging consumers to write more elaborate, realistic, and informative comments instead of using the platform to express emotions (Ruiz-Mafea, 2018). In this way, online reviews increase in quality and perceived helpfulness (RuizMafea, 2018). It is also meant to highlight that most reviews tend to be non-informative and could have fake content, leading to potentially harming the organization. The study also demonstrates that users that provide text and pictures are seen as more accurate and useful online reviews and leads to quicker decision-making of consumers (Ruiz-Mafea, 2018). The following factors were considered to be important in determing online review's quality:

1. Online review credibility: the overall opinion of what consumers thought about the review, whether the review was factual, accurate and credible;

2. Online review informativeness: this concerned the relevance, completeness, and timeliness of the review;

3. Online review helpfulness: whether consumers were not raised with any more questions after seeing the online review;

4. Online review persuasiveness: whether consumers were convinced with arguments after seeing the online review:

5. Empathy: the extent to which consumers felt concerned or moved by the review;

6. Emotions: these emotions were allocated into various categories such as angry/content, displeased/please, bored/entertained etc (RuizMafea, 2018).
This study helps understand the type of reviews that generate a positive decision-making process; this also applies to employees that work for an organization. Besides, according to a Bright Local Survey, $82 \%$ of potential employees read online reviews of the companies on employer review sites (Murphy, 2019). For this reason, it can be assumed that it affects corporate reputation. For example, according to Muse, it should be considered that a dissatisfied employee is more likely to post a negative review and express his frustration than a satisfied employee (Wolf, 2019). A satisfied employee is likely to tell three close friends about a positive experience in a company, whereas a dissatisfied employee could feel the need to let more people know about a bad experience in an organization (Wolf, 2019). For this reason, it could imply that negative reviews that are posted are usually intended to harm the organization (Wolf, 2019).

\subsection{Conclusion}

In conclusion, the literature discusses different methodologies on how corporate reputation is usually measured and recognized. Even though the research methodology in the abovementioned papers differs from what is done for our purpose, it can still guide as a foundation to explore trends and gaps in existing research. Conducting surveys for measuring reputation is seen as a popular method and has been exercised frequently by researchers. However, dimensions such as leadership, workplace, and governance could also be measured in online reviews (Fombrun, 2015). This new way of measuring corporate reputation could be seen as an advanced manner to show organizations that corporate reviews could potentially harm an organization. Importantly, an additional study shows that online reviews' perceived quality and trustworthiness of an organization is affected if reviews do not contain certain factors.

\section{RESEARCH METHODOLOGY}

The application that was developed for this research helps in recognizing negative reviews and can raise alarms for organizations. By offering an application that can perform sentiment analysis on online reviews, organizations will not fail to adapt to market changes. This section discusses the research approach, primary data collection as well as research methods applied. 


\subsection{Research approach}

This study applies text analysis. Text analysis is a research method that is being practiced to identify patterns of texts and uses both qualitative and quantitative research.

Qualitative research involves gathering and analyzing non-numerical data, understanding concepts, opinions, or experiences (Bhandari, 2020). An example of qualitative content analysis in this study is the exploration of Fombrun's dimensions in the review text. The words associated with these dimensions are a preliminary means to understand what employees are writing about whereafter sentiment analysis can be performed.

Quantitative research involves collecting and analyzing numerical data for statistical analysis (Bhandari, 2020). An example of quantitative research in this study is calculating the frequency of words used in a review, the sentiment of reviews from a particular organization, and the collection process of online reviews.

Since there is no existing literature on measuring corporate reputation with online reviews, this study intends to be exploratory.

The application should give directions to organizations, yet it could be developed to a further, more technical extent.

\subsection{Primary data collection}

In order to measure corporate reputation, primary data has been collected through the process of web scraping. Web scraping can be defined as the construction to download, parse, and organize data from a website in an automated manner (Broucke \& Baesens, 2018, pp 1-2). Web scraping is considered useful, especially for data scientists, because it provides a raw form of information (Broucke, 2018). However, structuring the data can be challenging (Broucke, 2018). Many data scientists use API's to scrape data (Broucke, 2018). An API is an Application Programming Interface that can be used as an instrument to access data in a more structured manner (Broucke, 2018). According to Indeed, the organization reserves the right to place limits on access to any API (without limitation on number of calls or requests) and monitor the usage to enforce these limits (Indeed, 2020). This means that websites such as Indeed do not provide API for free. In order to obtain an API from Indeed, it requires to become an editor. For that reason, web scraping has been utilized.
Indeed has been chosen as a target website because it is a popular international website, and there are a large number of corporate reviews available. Other websites, such as Glassdoor.com, were not chosen by us due to the scope of our research design. The collected data can be considered as primary because it is collected for the sole purpose of this study. For instance, many researchers use scraped data to develop deep learning models, natural language processing, and competitor analyses (Broucke, 2018).

Similarly, natural language processing is used for this research. It can be defined as the technology that aids computers in understanding human language (Garbade, 2018).

Before commencing the study, ethical clearance was sought because web scraping could be unethical, even illegal, if used for commercial purposes.

Moreover, the web scraping process started with analyzing the reviews beforehand. This process was completed by inspecting the HTML page and developing a spider, a Python code that extracts data from Indeed.nl.

For the web scraping process, Scrapy, a Python framework, was used. This framework is utilized for large scale web scraping and is frequently used by engineers because of its simplicity and easy access (Rizvi, 2017). Just as Scrapy, there are other scraping tools available such as Lxml, BeautifulSoup, MechnicalSoup, Python Requests, and others. Among these, Scrapy and Beautiful Soup tend to be popular among developers (Choudhury, 2020).

The reason for working with Scrapy is because the researcher was familiar with Scrapy before starting this project.

A few advantages of using Scrapy are:

1. Open-source framework.

2. An interactive shell console allows trying out the CSS and Xpath expressions to scrape data. If the right information extracts from the web page, the selectors are added to the spider.

3. Prior knowledge to use Scrapy was present.

4. Large community of developers

It is prevalent by developers to use Scrapy in a Conda environment because of its ease-of-use. However, for this particular project, Docker was used to ensure a well-functioning portable virtual environment. Using Docker, the researcher guaranteed that the software would behave in the same way, regardless of where it is developed (Anderson, 2016). This was done by creating multiple Docker containers. 
As mentioned, the prototype that was built is a web crawler that extracts data from Indeed.nl. This prototype is needed to collect data.

The collection of data consisted of 893 reviews.

Using Pandas, a Python library, the JSON data format was converted into a CSV. A python code enabled converting the data format because using a CSV format was preferred.

The reviews consisted of the following variables: title, author, review text, date, and rating. These variables were all variables that were available and were assigned to structured data columns.

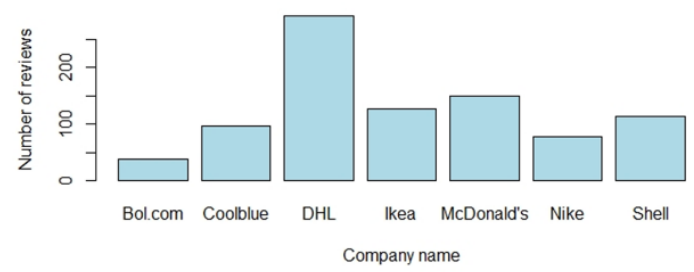

Figure 1. Number of reviews from indeed per organization.

In total, online reviews from seven organizations were scraped (see Figure 1); these companies were randomly selected. The organizations do not operate in a similar sector. The online reviews were from DHL (291 reviews), Coolblue (96 reviews), McDonald's (150 reviews), Bol.com (37 reviews), Nike (78 reviews), Ikea (127 reviews), and Shell (114 reviews).

The reviews were collected during April 2020.

\subsection{Research methods}

The first step in analyzing the data was to store the data in a relational database. Storing data in a database can be seen as vital because it can manage large amounts of data. If it is decided to reproduce this study on a larger scale, local file storage is not recommended (BBC, 2020). This step is necessary to ensure that the reviews were accessible from a database.

Just as for using Scrapy, a Docker container was created to work with PostgreSQL and PGadmin.

Since the dataset was relatively small, the data is managed with a local CSV file. After storing the data in a relational database, queries were created to find Fombrun's dimensions in the corporate reviews (Fombrun, 2015) with the following words that are associated with Fombrun's dimensions (Fombrun, 2015):
- Workplace: work, atmosphere, colleagues, fun, over time, building, and environment.

- Governance: ethics, open, transparent, fair in conducting business.

- Products \& Services: delivery, product, and service.

- Innovation: new, process, changes, and solution.

- Citizenship: process, human resources, law, and rules.

- Leadership: manager, boss, supervisor, and management.

- Performance: money, finance, sales, and salary.

The search for words and phrases that might have a meaning in the corporate reviews is called semantic search. Semantic search refers to understanding data and finding matches with components of data (Bast \& Bocchuld 2016). Semantic search is frequently used in Natural Language Processing to understand the meaning behind large amounts of text (Bast, 2016).

Concerning search quality, there are two main aspects: the matching between a keyword query and a document, and the ranking of the matching documents (Bast, 2016). With help from TSquery and TSvector in PostgreSQL, both matching and ranking search terms was provided in the prototype. These data types in PostgreSQL are used for full-text search (Patterson, 2019). The word associations were explicitly queried in order to make it visible what employees discussed on in reviews.

Words and phrases that were associated with Fombrun's dimensions were searched upon in Dutch.

The search for familiarity was a preliminary step in performing sentiment to explore which dimensions were involved.

Note that, importantly, before analysis, the dataset was checked for missing data. The data was structured with Python code that uses regular expressions from the re module to assure that sentiment analysis could be performed. The regular expressions were needed to ascertain that the data was accessible for analysis.

In addition, the Pandas library formed a basis to perform many tasks in structuring the data. For instance, Pandas was loaded to store the data in a column.

After this process, SpaCy was used to perform text analysis. SpaCy has grown in its popularity due to its ease-of-use and support of Natural Language Processing features (Broucke, 2018). SpaCy is an open-source natural language processing library for python. It is designed to help build applications that process large volumes of text (Broucke, 2018). 
To be able to run SpaCy, Python was installed, also in a Docker container. The reason for this is to provide a more consistent process.

SpaCy was used for the following functionalities:

- Language recognition, most reviews were Dutch, however it was seen that a few reviews were also in French and English.

- Removing stop words, required to perform text analysis because it eliminates unnecessary words.

- Tokenization, splitting the reviews into separate words.

Note that the use of SpaCy for natural language processing led to more accurate sentiment results. The use of tokenization and lemmatization (spreading sentences into words and using the root of a word) resulted in more accurate sentiment analysis.

After using SpaCY to prepare the text from the reviews, Pattern library was used to calculate sentiment, which gave two values: Polarity and Subjectivity. In Pattern, the sentiment object is used to find the polarity (positivity or negativity) of a text along with its subjectivity (Malik, 2020). The sentiment score is given between 1 and -1, depending on the positive or negative adjectives that are used. Also, subjectivity is a value between 0 and 1 . This is a quantification of the amount of personal opinion, and factual information found in the text (Malik, 2020).

It is useful to explore both polarity and subjectivity because reviews are usually based on personal opinion rather than factual information (Ruiz-Mafea, 2018).

In addition, a Python module LangDetect was used to recognize different languages in reviews. For instance, Pattern can be utilized in different languages. Therefore, the text needs to be recognized. LangDetect could recognize whether the reviews were in Dutch, English, or French. It should be noted that more languages could be applied, however, in our dataset these were not detected during processing. After applying SpaCy and language detection, Pattern was used to calculate sentiment.

After applying SpaCy and language detection, Pattern was used to calculate sentiment.

To summarize, three protoypes were built in our research:

1. Webcrawler prototype.

2. A prototype to do full text search with data stored in a relational database, PostgreSQL.

3. A protoype that performs text analysis and sentiment analysis.

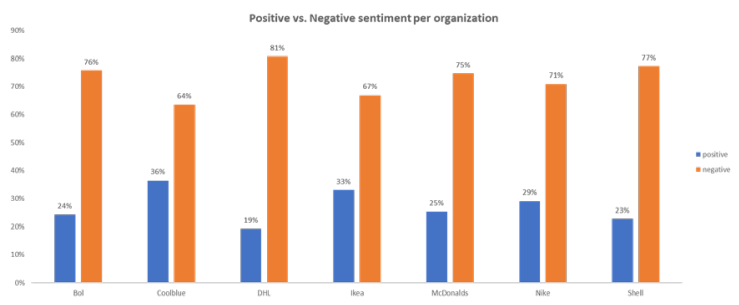

Figure 2. Averaged relative overall sentiment after full text search on relevant corporate reputation words per dimension per organization.

Figure 2 shows the measured division of positive and negative reviews amongst different organizations. Note that the organizations cannot be directly compared with each other because they do not operate in a similar sector and branch.

An overall observation from this graph is that most organizations are negatively reviewed. According to Muse, a dissatisfied employee is more likely to post a negative review and express his frustration than a satisfied employee (Wolf, 2019). A satisfied employee is likely to tell three close friends about a company's positive experience, whereas a dissatisfied employee could feel the need to let more people know about a bad experience in an organization (Wolf, 2019).

Thus, this could imply that negative reviews that are posted are usually intended to harm the organization and affect corporate reputation (Wolf, 2019).

The graph illustrates that DHL is the worstreviewed organization in our case study. $81 \%$ of all reviews from DHL are indicating as negative. On the contrary, Coolblue is considered the best-reviewed organization, even though $64 \%$ is negative.

\section{CONCLUSIONS}

The results of our research suggest that sentiment analysis is a useful approach to measure corporate reputation

In this study we have found that a high number of reviews were indicated to be negative. An explanation of this finding could be that employees are more likely to post a review after an unpleasant experience in an organization (Wolf, 2019).

While being aware of this, it is advised that organizations use our application to recognize negative reviews from an early stage.

\section{ACKNOWLEDGEMENTS}


Thanks go to Frederik Situmeang for providing some useful suggestions to an initial version of this manuscript.

\section{REFERENCES}

Anderson. (2016, november 4). Working with Docker containers. Retrieved from Digital Ocean: https://www.digitalocean.com/community/tutorials/wo rking-with-docker

Arruda, W. (2019, september 22). Why Online Employer Reviews Are Crucial To Your Branding. Retrieved from Forbes:

https://www.forbes.com/sites/williamarruda/2019/09/2 $2 /$ why-online-employer-reviews-are-crucial-to-yourbranding/\#1b61b9ea1f45

Bast, B. (2016). Semantic Search on Text and Knowledge Bases. Foundations and Trends in information retrieval, 156.

BBC. (2020). Databases and Data Capture. Retrieved from BBC:

https://www.bbc.co.uk/bitesize/guides/z8yg87h/revisio $\mathrm{n} / 4 \#: \sim:$ text $=$ Why\%20use $\% 20 \mathrm{a} \% 20$ database $\% 3 \mathrm{~F}$,edit $\% 20$ or $\% 20$ delete $\% 20$ old $\% 20$ data

Bhandari, P. (2020, 07 30). methdology. Retrieved from Scribbr: https://www.scribbr.com/methodology/qualitativeresearch/

Bronn. (2015). A Systems Approach to Understanding how Reputation Contributes to Competitive Advantage. Corporate Reputation review, 19.

Broucke, B. (2018). Practical Web Scraping for Data Science. Leuven.

Choudhury. (2020, april 08). Scrapy VS Beautiful Soup: A Comparison Of Web Crawling Tools. Retrieved from analyticsindiamag:

https://analyticsindiamag.com/scrapy-vs-beautifulsoup-a-comparison-of-web-crawlingtools/\#: : text=Scrapy\%20is\%20an\%20open\%2Dsourc e\%20framework $\% 2 \mathrm{C} \% 20$ whereas $\% 20$ Beautiful $\% 20 \mathrm{~S}$ oup $\% 20$ is, the $\% 20$ developer $\% 20$ what $\% 20$ they $\% 20$ nee d.

Courtright, S. (2009). leveraging organizational innovation for stategic reputation management. corporate reputation review, 26.

Davis. (2005). New Directions in Corporate Governance. annual review of sociology, 20.

Fombrun. (1996). Reputation: Realizing Value from the Corporate Image. Harvard Business Review.

Fombrun. (2015). Corporate Reputation Review: Stakeholder tracking and analysis: The RepTrak system for measuring corporate reputation. Macmillian Publishers, 22.

Garbade, D. M. (2018, October 15). A Simple Introduction to Natural Language Processing. Retrieved from Becoming Human: https://becominghuman.ai/a-simple-introduction-tonatural-language-processing-ea66a1747b32
Golafshani. (2003). Understanding reliability and validity in qualitative research. the qualitative report, p. 14

Indeed. (2020, March 30). Terms \& Conditions. Retrieved from Indeed:

https://www.indeed.com/legal?hl=en\&redirect=true\#a pi

Kircova, E. (2018). THE EFFECT OF CORPORATE REPUTATION ON CONSUMER BEHAVIOUR AND PURCHASE INTENTION. MANAGEMENT RESEARCH AND PRACTICE, 13.

Kotter. (1995). Leading Change: Why Transformatoin efforts fail. Harvard business review, 12 .

Lam-Lion, R. (2020, May 4). Scraping for masterproject. Retrieved from Rimtendo: https://rimtendo.com/masterproject/

Lange, L. D. (2011). Journal of Management Organizational reputation. Sage, 34.

Li, S. (2019, maart 18). A Complete Exploratory Data Analysis and Visualization for Text Data. Retrieved from Towards Data Science:

https://towardsdatascience.com/a-completeexploratory-data-analysis-and-visualization-for-textdata-29fb1b96fb6a

Malik, U. (2020). Python for NLP: Introduction to Pattern Library. Retrieved from Stack Abuse: https://stackabuse.com/python-for-nlp-introduction-tothe-pattern-library/

Mariconda, L. (2014). Being Known: A Literature Review on Media Visibility, Public Prominence and Familiarity with Implications for Reputation Research and Management. Corporate Reputation Review, 19.

Meents, V. H. (2020). AUAS-assignments Master Project. Amsterdam

Murphy, R. (2019). Local Consumer Review Survey. Retrieved from Brightlocal: https://www.brightlocal.com/research/local-consumerreviewsurvey/?SSAID $=314743 \&$ SSCID $=61 \mathrm{k} 4 \mathrm{~d} 7 \mathrm{wyr}$

Nolan, G. G. (2013). Examining How Corporations Use Online Job Ads to Communicate Employer Brand Image Information. Corporate Reputation Review, 14.

Orlitzky, S. (2012). Assessing stakeholder satisfaction: Toward a supplemental measure of corporate social performance as reputation. corporate reputation review, 19.

Patterson, J. (2019, August 1). full Text searching with Postgres. Retrieved from Forestry: https://forestry.io/blog/full-text-searching-withpostgres/

Perino, M. (2019, juni 25). 10 American companies with the worst reputations. Retrieved from Business Insider: https://www.businessinsider.nl/americancompanies-with-the-worst-reputations-2019-6/

Rizvi. (2017, july 26). Web Scraping in Python using Scrapy (with multiple examples). Retrieved from Analytics Vidhya: https://www.analyticsvidhya.com/blog/2017/07/webscraping-in-python-usingscrapy/\#: :text=Scrapy\%20is\%20a\%20Python $\% 20$ fra mework,your $\% 20$ preferred $\% 20$ structure $\% 20$ and $\% 20$ f 
ormat.\&text=Scrapy $\% 20$ is $\% 20$ that $\% 20$ framework.,ne ed $\% 20$ to $\% 20$ reinvent $\% 20$ the $\% 20$ wheel.

Ruiz-Mafea, C. C.-P. (2018). The role of emotions and conflicting online reviews on consumers' purchase intentions. Journal of Business Research, 9.

Sanders, A. (2016, november 14). What Is Semantic Search and What Should You Do About It? Retrieved from Moz: https://moz.com/blog/what-is-semanticsearch

Saunders. (2012). Research Methods for Business Students. In P. L. M. Saunders, Research Methods for Business Students (p. 467). Edinburgh Gate, Esses, United Kingdom: Pearson Education Limited.

Saunders, P. L. (2012). Research Methods for Business Students. In P. L. Saunders, Research Methods for Business Students (p. 729). England: Pearson Education unlimited.

Shayaa, J. b.-G. (2018). Sentiment Analysis of Big Data: Methods, Applications, and Open Challenges. Digital Object Identifier, 22.

Sheedy, G. (2018). A view from the inside. Corporate Governance, an international review, 20.

Smith, S. W. (2010). Does brand management of corporate reputation translate into higher market value? Journal of Strategic Marketing, 22.

Smitha, S. W. (2010). Does brand management of corporate reputation translate into higher market value? Journal of Strategic Marketing, 22.

Wen, Y. R. (2014). Sentiment Analysis in MOOC Discussion Forums: What does it tell us? Educational data mining, 8 .

Wendy Salomon. (2014, October 23). UNCOMMON SENSE: HOW DO YOU MEASURE REPUTATION? Retrieved from Nielsen: https://www.nielsen.com/us/en/insights/article/2014/u ncommon-sense-how-do-you-measurereputation/\#: :text=Measuring\%20 corporate\%20reput ation $\% 20$ effectively $\% 20$ shows, $\%$ E2 $\% 80 \% 9$ Cprogram $\%$ 2Ddriven $\%$ E2\%80\%9D\%20discipline.

Wolf, K. D. (2019). Should You Believe Company Reviews? Retrieved from Muse: https://www.themuse.com/advice/should-you-believecompany-reviews

Xianghua. (2012). Multi-aspect sentiment analysis for Chinese online social reviews based. Knowledge-Based Systems, 10. 